\title{
Giant Breast Hamartoma: A Case Report in Togo
}

\author{
Bidamin N’timon ${ }^{1 *}$, Tchin Darré2, Massaga Dagbé1, Pihou Gbandé3, Abdoulatif Amadou4, \\ Mazamaesso Tchaou ${ }^{3}$, Lantam Sonhaye ${ }^{4}$, Samadou Aboubakari5, Dédé Ajavon ${ }^{5}$, Akila Bassowa ${ }^{5}$, \\ Lama Kègdigoma Agoda-Koussema ${ }^{3}$, Komlanvi Adjenou ${ }^{4}$
}

\author{
${ }^{1}$ Department of Radiology, University Teaching Hospital of Kara, Kara, Togo \\ ${ }^{2}$ Department of Pathology, Sylvanus Olympio University Teaching Hospital of Lomé, Lomé, Togo \\ ${ }^{3}$ Department of Radiology, Sylvanus Olympio University Teaching Hospital of Lomé, Lomé, Togo \\ ${ }^{4}$ Department of Radiology Campus University Teaching Hospital of Lomé, Lomé, Togo \\ ${ }^{5}$ Department Obstetrics and Gynecology, University Teaching Hospital of Kara, Kara, Togo \\ Email: ${ }^{*}$ cntimon@yahoo.fr
}

How to cite this paper: N'timon, B., Darré, T., Dagbé, M., Gbandé, P., Amadou, A., Tchaou, M., Sonhaye, L., Aboubakari, S., Ajavon, D., Bassowa, A., Agoda-Koussema, L.K. and Adjenou, K. (2018) Giant Breast Hamartoma: A Case Report in Togo. Open Journal of Radiology, 8, 30-36. https://doi.org/10.4236/ojrad.2018.81004

Received: January 4, 2018

Accepted: March 10, 2018

Published: March 13, 2018

Copyright (C) 2018 by authors and Scientific Research Publishing Inc. This work is licensed under the Creative Commons Attribution International License (CC BY 4.0).

http://creativecommons.org/licenses/by/4.0/

\begin{abstract}
We report the case of a 50-year-old patient, who was explored in mammography, ultrasound and CT for a large painful mass of the right breast that had been evolving for 30 years and gradually increasing in size. There was a typical "sausage slice" appearance with clear center macrocalcifications on the mammogram; an aspect of "breast in the breast" on ultrasound. The scanner had made it possible to specify the dimensions of the mass, which measured $21.4 \mathrm{~cm}$ in height; $18.6 \mathrm{~cm}$ wide and $9.5 \mathrm{~cm}$ thick. Histology after exeresis noted the adenolipofibromatous nature of the mass.
\end{abstract}

\section{Keywords}

Mammography, Ultrasound, Hamartoma, Togo

\section{Background}

Mammary hamartomas are a set of rare benign breast tumors, representing approximately $4.8 \%$ of all benign tumors of the breast [1]. These are lesions consisting of glandular, adipose and fibrous tissues in often abnormal proportions [1] [2]. These are rare lesions whose pathological appearance is not distinctive although they may have some radiological features [3]. Most reported cases are small to moderate with a size often between 1.2 and $14 \mathrm{~cm}$ and an average of 3.8 $\mathrm{cm}$ [4]. Giant hamartomas with chronic evolution are rare. We present a clinical radio file of giant hamartoma of the breast evolving for 30 years in a patient of 
50 years.

\section{Case Report}

A 50-year-old Mrs. L. O, housewife, married, living in precarious conditions, fifth parapopal gesture, menopausal for 16 years, with no history of surgery or chronic pathology, presented a painful mass of the hypertrophied right breast, evolving for about 30 years. The pain was moderate (3/10 on the numerical scale), intermittent and had been treated with analgesics. This mass appeared at the age of 20 at the end of the first trimester of her second pregnancy. It gradually increased in size especially during the following pregnancies and at the time of breastfeeding. After several medical consultations, surgical treatment was proposed but refused by the patient. The persistence of the pains and the discomfort of this hypertrophy of the right breast had motivated a new consultation. There is no concept of hormone replacement therapy or a history of breast cancer in the family.

The physical examination noted a large right breast hanging with the lower limit at the height of the ipsilateral iliac crest (Figure 1). No changes in the skin and nipple were observed outside of a wart in the super-outer quadrant. The mass measured 20 centimeters long axis and 10 Centimeters small axis around. The mass was firm, relatively mobile in relation to the shallow and deep planes and predominantly in the outer quadrants. The left breast was of normal size. Axillary hollows were free.

A mammogram performed on a mammograph ALPHA brand had scored breasts classified BIRADS 2 on the right and BIRADS 1 on the left. It was noted in the right breast, a heterogeneous mass well delimited by a thin opaque border corresponding to the capsule, in which are juxtaposed fat clarifications and tissue opacities of medium tonalite giving a typical appearance in "sausage slice"
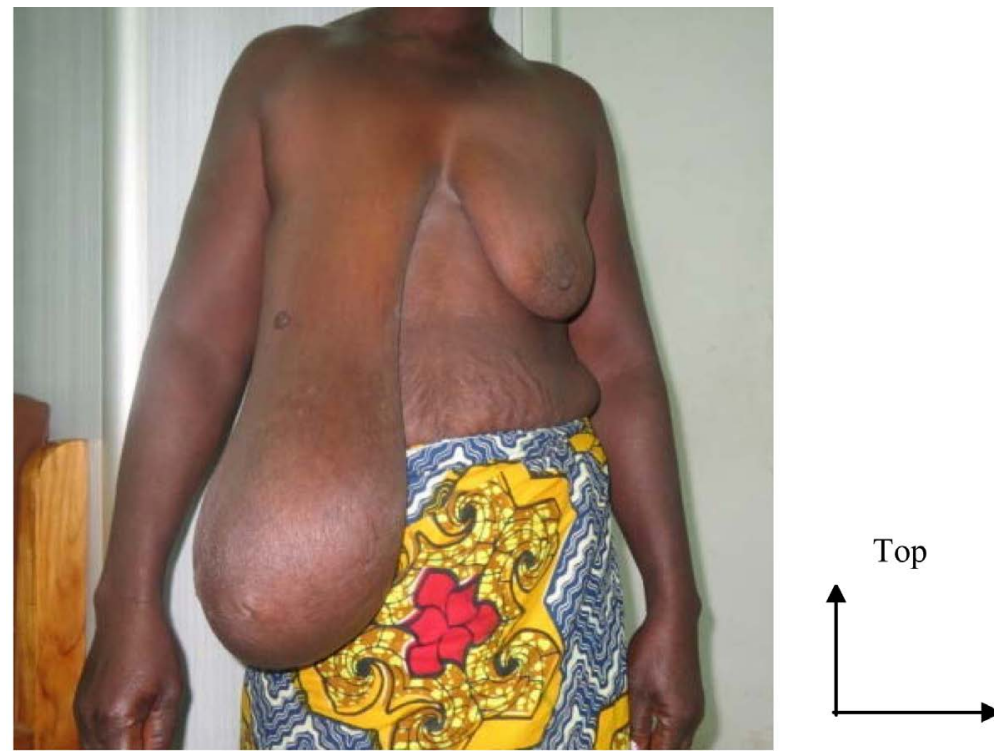

Left

Figure 1. Photograph showing a right gigantomastia, normal volume left breast. 
(Figure 2). There were also macrocalcifications within this mass. The dimensions of this mass were difficult to specify on the clichés. There were no intra-mammary microcalcifications or adenomegalies in the axillary extensions. This mass was classified ACR 2. Complementary breast ultrasound using a 7.5 MHZ probe on a General Electric model ${ }^{\text {ru }} 200$ model echograph confirmed the delineation of the right breast mass by a thin capsule. The echostructure of this mass was heterogeneous made of fatty tissue and fibroglandular similar to that of the normal breast giving the aspect of "breast in the breast". (Figure 3). A

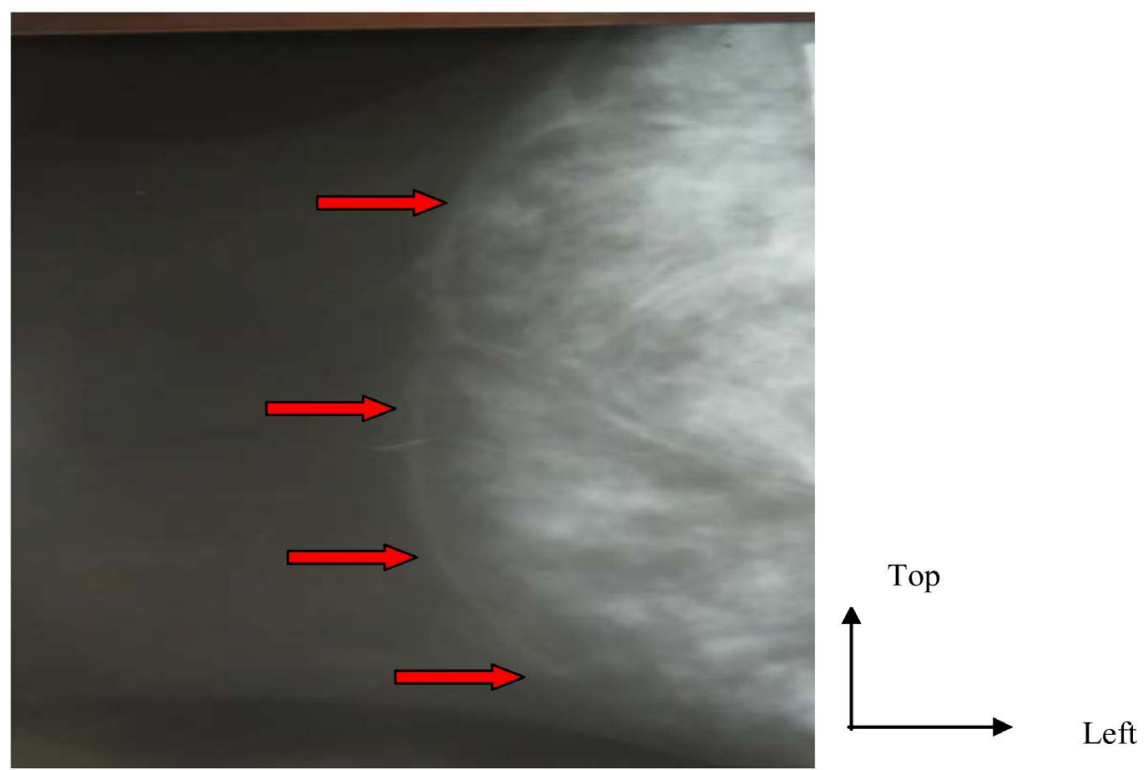

Figure 2. Facial incidence of the lower extremity mammogram showing upper limits of mass with thin capsule (red arrows).

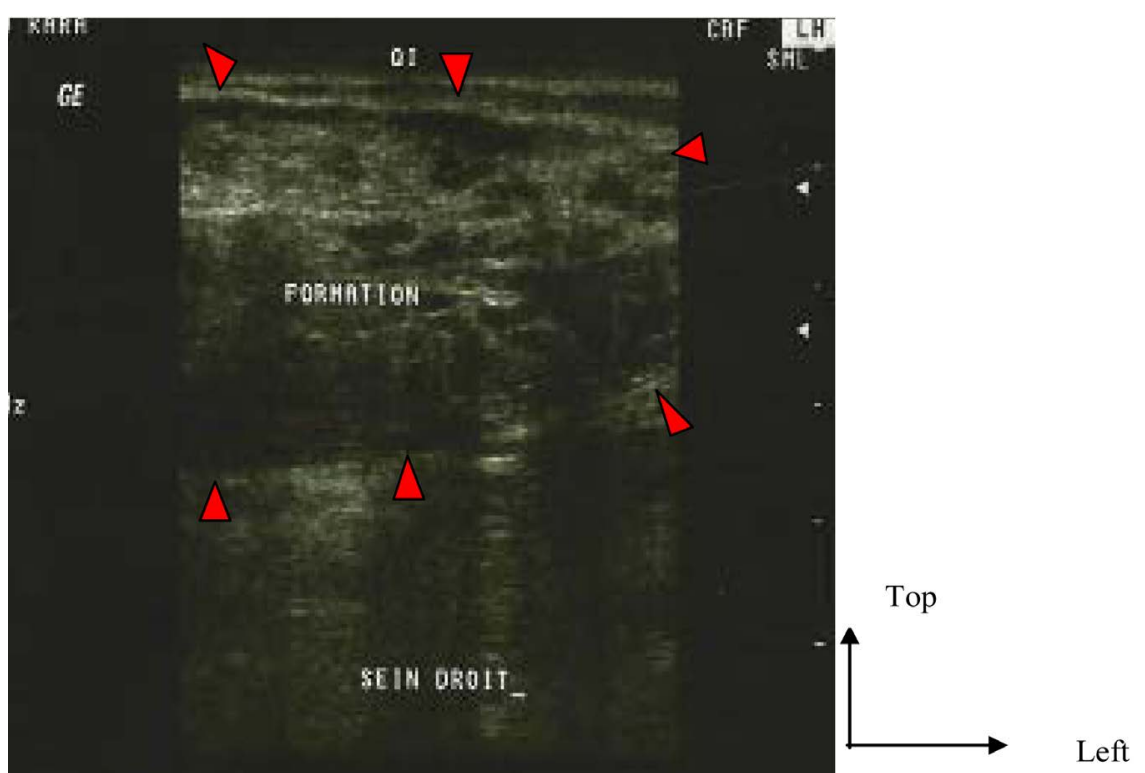

Figure 3. Ultrasound section of the right breast showing part of the breast mass well encapsulated (red arrows head). 
computed tomography of the breasts without injection of the contrast medium noted a breast mass well limited by a thin dense capsule. It contained greasy clarifications and tissue glandular opacities as well as some macrocalcifications. It was $21.4 \mathrm{~cm}$ high; $18.6 \mathrm{~cm}$ wide and $9.5 \mathrm{~cm}$ thick (Figure 4). No axillary adenomegaly was found. The left breast was normal (ACR1). The diagnosis of giant hamartoma of the right breast had been poses.

An excision of the mass had brought back a voluminous well encapsulated nodule. The postoperative course was simple.

Histology confirmed the diagnosis by describing mammalian lobules of conserved morphology, dispersed within fibro-hyaline connective tissue with adipose tissue insinuating between fatty lobules.

\section{Discussion}

Described for the first time in 1971 by Arrigoni et al. [5], hamartoma of the breast is a rare benign breast tumor [6] [7] [8]. Its frequency is between $0.04 \%$ $1.15 \%$ and it represents $4.8 \%$ of all benign breast tumors [6] [9]. It can be diagnosed at any age from puberty. In the majority of cases, it is seen in women aged over 35, with extremes ranging from 16 to 76 years [4] [10]. The lesion occurred in our patient at a relatively young age (20 years). Whether hamartoma is found in an elderly patient or younger, a common trait is that this benign tumor develops before menopause [11]. Clinically, hamartoma can evolve in an occult or asymptomatic manner [1] [8] [12], which is then often the object of fortuitous discovery [12]. It can be associated with a mastodynia. The hamartoma is revealed most of the time during a palpation as a firm nodule, mobile benign characters such as adenofibroma [4] [10] [13] and this was the case of our patient.

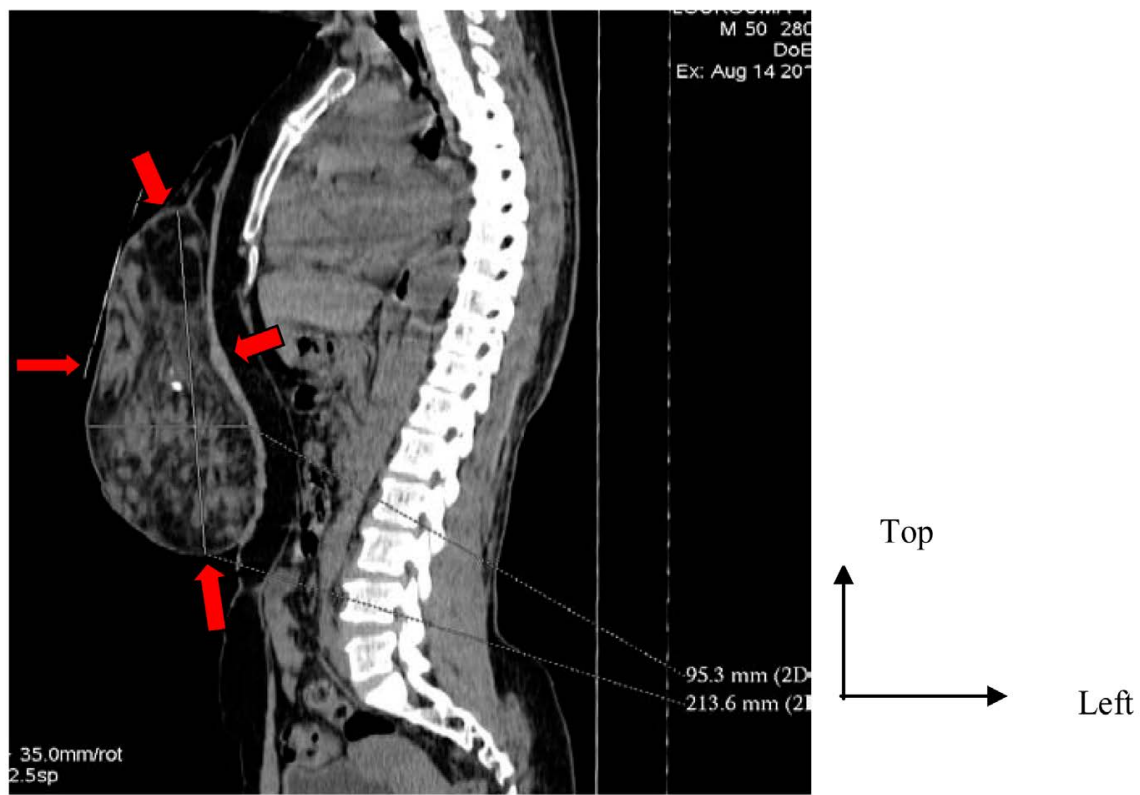

Figure 4. Non-injected thoracic CT, Sagittal reconstruction by the right breast showing the large, well-encapsulated heterogeneous mass (red arrows). 
In addition, the absence of axillary adenomegaly, a criterion of benignity noted in our patient has also been reported [1] [12]. Some bilateral forms have been described [7]. The onset of signs can range from two months to two years [7] before diagnosis or even more as in our patient with a chronic course in thirty years marked by painful episodes during pregnancy. This is a particular character emphasized by this radio-clinical case; late use of appropriate care is an African trait. Another peculiarity of our observation and the most important is the large size of the hamartome which measured $216 \mathrm{~mm} \times 186 \mathrm{~mm} \times 94 \mathrm{~mm}$. Work has described variable sizes ranging up to a maximum of $14 \mathrm{~cm} \mathrm{[10]} \mathrm{or} 17$ $\mathrm{cm}$ [14]. A hamartoma similar in size to our case had never been described before.

In terms of imaging, the radiological aspects depend on the contents of the hamartoma. Several aspects have been described in mammography including the pathognomonic found in mixed or adipose hamartomas, which is sufficient to carry the diagnosis without further exploration [1] [5] [12]. It is an opacity of variable size, well limited, surrounded by a hyperdense border corresponding to a pseudo capsule with partially greasy content sometimes with calcifications giving an aspect of "breast in the breast" or "slice of sausage". It is this aspect that has been observed in our case. In some types of hamartoma, the mammography appearance is that of a lipoma [1]

Ultrasonography is useful in some cases to guide the biopsy and shows a benign type mass: round or oval, poorly contrasted, well encapsulated with an echogenicity close to the surrounding normal tissue that is repressed [10] [12] [15]. The well encapsulated character giving the appearance of "breast in the breast" was clearly visible in our patient. We performed a breast computed tomodensitometry in our patient in order to have the precise dimensions of the mass; our mammograph is not equipped with a Potter adapted for the large breast size. The use of Magnetic Resonance Imaging mammography can be useful in some forms indeterminate mammography and ultrasound [8] [11]. It shows a well-defined lesion of homogeneous hyposignal T1 that enhances homogeneously after injection of contrast medium with a non-enhanced peripheral border [16]. Biopsy or excision with histological examination is not necessary for the diagnosis [8], but allows to affirm the benignity because rare cases of carcinomatous degeneration have been reported [3] [8].

Surgical removal is the curative method of hamartomas of the breast [1] [2]. It is not systematic. However it can be discussed in case of desire of the patient, aesthetic discomfort or monitoring difficulties [6]. In our observation it was done for aesthetic reasons but mainly because of the pain that became recurrent and increasingly important.

\section{Conclusion}

The diagnosis of breast hamartoma remains based on mammography coupled with ultrasound. Certainty of benignity remains the prerogative of histology 
since co-existing carcinomas have been described. Our observation is peculiar by the size of the lesion, its very late diagnosis and the chronic evolution for 30 years before treatment.

\section{Conflicts of Interest}

The authors report no conflict of interest.

\section{Authors Contributions}

BN was responsible for the design of the study, undertook the field study, performed data collection, analysis and interpretation, and wrote the manuscript.

TD, MD, PG, AA, TM, LS, SB and AB: participated in the design of the study, supervised the data collection and participated in the data analysis. LKAK is responsible for the overall scientific management of the study, the analysis and interpretation, and preparation of the final manuscript. All authors have read and approved the final manuscript to be submitted for publication.

\section{References}

[1] Sonmez, F.C., Gucin, Z., Yildiz, P. and Tosuner, Z. (2013) Hamartoma of the Breast in Two Patients: A Case Report. Oncology Letters, 6, 442-444. https://doi.org/10.3892/ol.2013.1366

[2] Guray, M. and Sahin, A.A. (2006) Benign Breast Diseases: Classification, Diagnosis, and Management. Oncologist, 11, 435-449. https://doi.org/10.1634/theoncologist.11-5-435

[3] Tse, G.M.K., Law, B.K.B., Pang, L.M. and Cheung, H.S. (2002) Ductal Carcinoma In Situ Arising in Mammary Hamartoma. Journal of Clinical Pathology, 55, 541-542. https://doi.org/10.1136/jcp.55.7.541

[4] Tse, G.M., Law, B.K., Ma, T.K., Chan, A.B., Pang, L.M., Chu, W.C. and Cheung, H.S. (2002) Hamartoma of the Breast: A Clinicopathological Review. Journal of Clinical Pathology, 55, 951-954. https://doi.org/10.1136/jcp.55.12.951

[5] Arrigoni, M.G., Dockerty, M.B. and Judd, E.S. (1971) The Identification and Treatment of Mammary Hamartoma. Surgery, Gynecology \& Obstetrics, 133, 577-582.

[6] Magdalene, K.F., Robin, G. and Sapna, M. (2014) Mammary Hamartoma-A Clinical Dilemma. Gulf Journal of Oncology, 1, 87-90.

[7] Barbaros, U., Deveci, U. and Erbil, Y. (2005) Breast Hamartoma: A Case Report. Acta Chirurgica Belgica, 6, 658-659. https://doi.org/10.1080/00015458.2005.11679798

[8] Boufettal, H., Mahdaoui, S. and Noun, M. (2010) Breast Hamartoma. Feuillets de Radiologie, 50, 189-191. https://doi.org/10.1016/j.frad.2010.05.004

[9] Donya, F., Janbakhsh, H. and Emad, A. (2011) Breast Hamartoma: Mammographic Findings. Iranian Journal of Radiology, 8, 258-260. https://doi.org/10.5812/iranjradiol.4492

[10] Oueslati, S., et al. (2007) Hamartome du sein. Imagerie de la Femme, 17, 19-25. https://doi.org/10.1016/S1776-9817(07)88603-2

[11] Mizuta, N., Sakaguchi, K., Mizuta, M., Imai, A., Nakatsukasa, K., Morita, M., et al. (2012) Myoid Hamartoma of the Breast That Proved Difficult to Diagnose: A Case 
Report. World Journal of Surgical Oncology, 10, 12.

https://doi.org/10.1186/1477-7819-10-12

[12] Vergine, M., Scipioni, P., Santucci, E., et al. (2013) Harmatoma of the Breast in a Young Woman. Case Report. Il Giornale di Chirurgia, 34, 161-163.

[13] Gatti, G., Mazzarol, G., Simsek, S. and Viale, G. (2005) Breast Hamartome: A Case Report. Breast Cancer Res Treat, 89, 145-147. https://doi.org/10.1007/s10549-004-1656-6

[14] Rosen, P.P. (1996) Benign Mesenchymal Neoplasms. In: Rosen, P.P., Ed., Breast Pathology, Lippincott-Raven, Philadelphia, 676-681.

[15] Park, S.Y., Oh, K.K., Kim, E.K., Son, E.J. and Chung, W.H. (2003) Sonographic Findings of Breast Hamartoma: Emphasis on Compressibility. Yonsei Medical Journal, 44, 847-854. https://doi.org/10.3349/ymj.2003.44.5.847

[16] Erdem, G., Karakaş, H.M., Işık, B. and Fırat, A.K. (2011) Advanced MRI Findings in Patients with Breast Hamartomas. Diagnostic and Interventional Radiology, 17, 33-37. 